\title{
Family Medicine: Preparing for a High-Performance Health Care System
}

Karen Davis, PhD, and Kristof Stremikis, MPP

As policy leaders seek to lower costs, increase access, and improve quality in the American health care system, strengthening primary care has become a key strategy for achieving high performance. Health reform proposals under consideration in Congress include provisions that increase Medicare and Medicaid payment rates for prevention and primary care services, spread the patientcentered medical home (PCMH) model in the Medicare program, and create a payment innovation center to test and share savings with innovative primary care practices. ${ }^{1}$ There is wide consensus that primary care is at the center of a high-performing health care system.

The health professional community is leading change. The Future of Family Medicine report in 2004 set forth a new model of family medicine that is the foundation of a high-performance health system. ${ }^{2}$ In 2007,4 primary care professional associations endorsed joint principles for the PCMH. ${ }^{3}$ Policy leaders have responded to the argument for the benefits to patients and the nation from a new model of care, and they are increasingly willing to commit resources to primary care with the expectation that such investment will yield returns not only in better care for patients, but also in greater value for the resources dedicated to health care. Primary care will need to undergo fundamental change in the design and delivery of care to meet these high expectations. The National Demonstration Project, launched by the American Academy of Family Physicians in 2006, is already gaining valuable experience with transforming care delivery and yielding important lessons. ${ }^{4}$

From the Commonwealth Fund, New York, New York. Funding: none.

Conflict of interest: K. Davis is a member of the Board of Directors of Geisinger Health System.

Corresponding author: Karen Davis, $\mathrm{PhD}$, The Commonwealth Fund, One East 75th Street, New York, NY 10021 (E-mail: kd@cmwf.org).

\section{How Does the United States Compare on Attributes of Patient-Centered Primary Care?}

Despite the leadership of the health professional community, change is difficult and resistance can be expected. Perhaps the greatest barrier to change is a belief that physicians are already delivering patient-centered care. A review of the performance of the health system along key dimensions is, therefore, instructive in identifying gaps in performance that can be addressed by a new model of care. In 2005, my colleagues and $\mathrm{I}^{5}$ set forth a "2020 Vision of Patient-Centered Primary Care," with 7 attributes of patient-centered primary care that are likely to yield cost and quality outcomes valued by patients and sought by policy leaders. These include:

- superb access to care;

- patient engagement in care;

- clinical information systems;

- care coordination;

- integrated, comprehensive care;

- ongoing, routine patient feedback; and

- publicly available information about practices.

This list builds on several decades of professional research and recommendations that identify prioritized areas for measurement and improvement. ${ }^{6-9}$ Family physicians in a high-performance health care system will need to deliver on all 7 metrics to provide care that is truly patient centered.

The United States lags far behind other countries on many of these 7 attributes of patient-centered primary care. Access is a particular problem in a country that remains the only industrialized nation that does not guarantee its citizens access to basic medical care. ${ }^{10}$ Only two thirds of American adults younger than age 65 report having an accessible primary care provider. ${ }^{11}$ In addition, nearly three quarters of all adults were not able to see their doctor quickly (ie, the same or day or the next day) when they fell sick, found it difficult to get through 
to their doctors by phone, or said it was difficult to get care after regular work hours without going to the emergency department. ${ }^{12}$

Patient engagement in care in the United States is mixed relative to international benchmarks. Just more than half of those with complex medical needs report that their regular doctor always explained treatment options and involved them in decision making, well beneath comparable rates in the Netherlands and New Zealand. ${ }^{13}$ Meanwhile, according to a recent Commonwealth Fund survey of primary care physicians, just half of patients in the United States received reminder notices for preventive or follow-up care. ${ }^{14}$ One bright spot is the number of sicker American adults who were provided with written plans to manage their care at home- $66 \%$ of respondents in the United States received written instructions, compared with less than half of those in 7 other industrialized countries. $^{13}$

Clinical information systems such as electronic medical records hold great promise for improving quality and lowering costs by facilitating quality reporting and improvement activities, empowering individual patients, and expanding provider access to evidence and clinical decision-support tools. ${ }^{15}$ The United States is far behind the Netherlands, New Zealand, the United Kingdom, Australia, and Germany on the adoption of electronic medical records and the functionality of health information technology in the primary care setting. ${ }^{16}$ The contrast between the United States and the Netherlands is particularly stark, with $98 \%$ of Dutch primary care physicians reporting the use of electronic medical records compared with only $28 \%$ of their American counterparts. This general pattern persists when examining the prevalence of other information technology functions, such as electronic prescribing, decision support, and computerized access to test results.

Fragmentation within the US care delivery system leads to waste, duplication, and substandard outcomes that are not only expensive, but dangerous. ${ }^{17}$ A recent Commonwealth Fund study showed that nearly half of all adults have experienced at least one care coordination problem, including not being contacted about test results and primary care and specialist doctors failing to share information. ${ }^{18}$ The United States also trails international peers on key measures of care coordination, including health records being available dur- ing visits and undergoing duplicative medical tests. $^{12}$

Numerous Commonwealth Fund case studies have shown that integrated, comprehensive care delivery models reduce care coordination problems and ultimately improve patient experience while lowering costs. ${ }^{19}$ Care management by support staff is an important indicator of integration and one strategy for smooth information transfer among medical teams. Thirty-three percent of sicker adults report that a nurse is regularly involved in the management of their treatment. ${ }^{13}$ The United Kingdom leads among 7 other industrialized nations, with $48 \%$ of respondents reporting nurse-based care management.

The United States also trails the United Kingdom in the number of family medicine physicians that report receiving data about patients' clinical outcomes and surveys of patient satisfaction and experiences. Just $43 \%$ of American primary care physicians reported receiving clinical outcome data compared with $78 \%$ in the United Kingdom. ${ }^{14}$ Meanwhile, $48 \%$ of primary care doctors in the United States receive patient satisfaction surveys compared with $89 \%$ of those in the United Kingdom.

Finally, a high-performing health system provides cost and quality information about practices so that patients can make informed decisions when choosing among health care providers. Currently, no federal all-payer database exists for patients who want to know and compare the relative performance of physicians. ${ }^{20}$ Again, the United States trails other industrialized countries in health systems innovation; in the United Kingdom, this type of information is available through the Internet. ${ }^{21}$

In short, reform of the US financing and delivery system is needed to improve the accessibility and accountability of primary care. Reform that provides the financial and technical assistance necessary to overcome these shortcomings must improve patients' experiences of care, clinical outcomes, and physician satisfaction with the practice of medicine.

\section{What Are the Models: How Can the United States Improve Performance?}

During the past 3 years, numerous demonstrations of the PCMH model have been implemented. The first national demonstration project, Trans- 
forMED, sponsored by the American Academy of Family Physicians, was launched in 2006 and engaged 36 family medicine practices in transformation of care during a 2-year period. Eighteen practices received facilitated implementation of the TransforMED patient-centered model and 18 practices engaged in self-directed implementation. The goal of the demonstration was to assess the usefulness and impact of the PCMH on quality of care and business performance.

The model included components on access to care and information (eg, same-day appointments); practice management (eg, optimized office design); practice services (eg, prevention screening and services); health information technology (eg, including not only automated systems and support for physicians but patient portal access to information); care management (eg, managing a population of patients, including outreach to ensure wellness promotion, disease prevention, and chronic disease management); quality and safety (eg, medication management and feedback about patient satisfaction); continuity of care (eg, collaborative relationships with providers external to the practice, such as hospital care, behavioral health care, and physical therapy); and practice-based team care (eg, task designation by skill set). ${ }^{22}$

Participants were assisted with identifying the most efficient and effective way to implement transformative practice redesign. Initial evaluation results have produced lessons useful for practices that wish to engage in transformation, and enhancement tools and processes have been developed to assist practices across the country. An evaluation of the impact of the new model on quality of care and business performance is ongoing. The Commonwealth Fund provided funding for the patient experience component of the evaluation.

A recent evaluation of a PCMH demonstration within Group Health Cooperative in a metropoli$\tan$ Seattle clinic shows encouraging results. ${ }^{23} \mathrm{~A}$ practice serving 9200 adult patients was redesigned using the principles of a PCMH. Change components included: structural and team changes (eg, size of patient panels reduced from 2327 to 1800 , scheduled visits increased from 20 to 30 minutes, dedicated "desktop medicine" time, and increased staffing); point-of-care changes (eg, real-time specialist consulting and extensive use of electronic information systems); patient outreach changes (eg, reminders, emergency visit follow-up, abnormal test result follow-up); and management changes (eg, daily team huddles, rapid process improvement cycles). The intervention was motivated in part by a desire to decrease primary care physician dissatisfaction caused by large patient panels and heavy workload.

The evaluation compared patients in the clinic before and after implementation in 2007 with patients in 19 other clinics (or 2 clinics in the case of patient and clinician surveys). The intervention practice experienced significantly improved results on the clinical quality of care; patient experiences (eg, quality of doctor-patient interactions, shared decision making, coordination of care, access, patient activation/involvement, and goal setting/tailoring); reduced clinical staff emotional exhaustion for physicians and physician assistants; and reduced use of emergency services by patients. ${ }^{23}$ Savings from reduced use of emergency departments were offset by higher payments to primary care. In other words, the intervention improved patient experiences, clinical outcomes, and clinician satisfaction at no additional cost.

The Geisinger Health System in rural northeastern Pennsylvania has also begun implementing a medical home program. Their "personal health navigator" model is targeted to high-risk Medicare patients and is motivated in part by a desire to reduce expenditures for Medicare beneficiaries covered either by the Geisinger Medicare Advantage health plan or by Geisinger participation in the Medicare Physician Group Practice Demonstration, which provides shared savings to practices by slowing the growth in Medicare outlays. The model has been implemented on a staggered rollout basis in 2 practices (one initiated in October 2006 and the other in January 2007). Each site typically has 5 to 7 physicians, physician assistants, or advanced practice nurses serving 1500 to 2000 Medicare patients.

Components of the Geisinger model include: patient-centered primary care team practice (including an embedded nurse who was previously with the Geisinger disease management program); integrated population management (eg, case management, remote monitoring, transitions of care management, and pharmaceutical management); microdelivery systems (eg, value-based referral system); performance reporting (eg, regular reporting and review of quality metrics and patient satisfaction); and value reimbursement (practices receive 
$\$ 5000$ per month per 1000 Medicare members to help finance additional staff, support extended hours, and other practice infrastructure changes and $\$ 1800$ per physician per month).

A primary target outcome for the Geisinger medical home program is reduced hospital utilization. Preliminary data after 1 year show a $20 \%$ reduction in hospital admissions and $7 \%$ savings in total per-member per-month medical costs. ${ }^{24}$ Based on this success, Geisinger has expanded the initiative to a total of 11 practice sites.

Some private insurers are beginning to support medical home initiatives. In Iowa, Wellmark Blue Cross and Blue Shield is supporting a medical home demonstration project to promote patientphysician collaboration and care coordination, providing financial rewards for physicians who excel at diabetes care. It also sponsors learning collaboratives to help primary care practices establish teams to improve the quality of diabetes care through process improvement and disease management techniques. ${ }^{25}$ Blue Cross Blue Shield of North Dakota has supported a pilot program with a chronic disease management nurse stationed in a MeritCare primary care clinic. Preliminary results include a $6 \%$ reduction in hospital admissions, a $24 \%$ decrease in emergency department visits, and a reduction of per-member costs of $\$ 530$ annually. ${ }^{26}$ Blue Cross Blue Shield of Michigan allocated \$64 million in fiscal year (FY) 2009 to an incentive pool to reward practices building medical home capability after seeing significant cost and quality improvements under the Physician Group Incentive Program and PCMH Initiative the prior year. ${ }^{27}$ The Commonwealth Fund is funding ongoing evaluations of medical home initiatives, with participation of private payers in Colorado, Massachusetts, New York, Ohio, and Rhode Island.

The Commonwealth Fund is also supporting technical assistance to 68 safety net clinics in 5 states to help them become PCMHs. The goal of the initiative is to develop and demonstrate a replicable and sustainable implementation model to transform safety net primary care practices into PCMHs and to achieve benchmark performance in quality, patient experience, and efficiency. The initiative is being undertaken by Qualis Health with the assistance of the MacColl Institute for Health Care Innovation and regional coordinating centers in each of the 5 states. The 5 -year initiative was launched in 2009. An evaluation is being under- taken by a team headed by Marshall Chin, MD, at the University of Chicago.

With Commonwealth Fund sponsorship, the National Academy of State Health Policy is partnering with states interested in spreading the PCMH model. Thirty-one states are also currently working to advance medical homes in Medicaid or the Children's Health Insurance Program. ${ }^{28}$ Perhaps the oldest and best known initiative is Community Care of North Carolina, which supports 14 networks that blanket the state and engages 3,200 physicians serving 800,000 Medicaid patients. The state Medicaid program provides financial support of $\$ 3$ per Medicaid beneficiary per month to each network. The networks hire case managers and medical management staff who work on care improvement for asthma, diabetes, and the screening/ referral of young children with developmental problems. Case managers also identify and facilitate management of costly patients. In addition, the state pays primary care practices $\$ 2.50$ per Medicaid beneficiary per month to serve as a medical home and to participate in disease management. Estimated savings to the Medicaid program were $\$ 60$ million in FY 2003; \$124 million in FY 2004; $\$ 77$ to $\$ 85$ million in FY 2005; and $\$ 154$ to $\$ 170$ million in FY 2006. ${ }^{29}$

Vermont is also moving to support medical homes as part of its Blueprint for Health initiative. Pilot programs in 3 counties involve private insurers, Vermont Medicaid, and Medicare with enhanced reimbursement on top of negotiated rates to providers that meet certain medical home standards. The program also incorporates direct financial assistance to local multidisciplinary community care teams that extend support to participating medical practices through direct services, care coordination, population management, and quality improvement activities. ${ }^{25}$

Similar efforts can be found in other countries. In 2000 Germany launched disease management programs and clinical guidelines for chronic care, with financial incentives from insurance funds to develop and enroll patients and to be held accountable for care. Providers receive financial incentives for enrolling patients and for offering chronic care services like patient self-management education. Early results show positive effects on quality. ${ }^{30}$

Although most of these initiatives are in early stages, the preliminary evaluation results are encouraging. That the specific model and interven- 
tion varies widely from initiative to initiative is notable. Most practice sites engaged in pilot programs benefit from extensive support, whether financial payments, technical assistance, or in-kind assistance. In some cases, primary care practices are part of larger integrated delivery systems that are able to provide information systems, quality improvement, care process redesign, and financial rewards for assuming this expanded role.

\section{Policies to Advance the Spread of PCMHs}

The goals of reforming the delivery of primary care are to (1) improve the accessibility and coordination of care for patients; (2) increase accountability for health outcomes and the receipt of essential preventive and chronic care; (3) reduce avoidable utilization of care (eg, emergency department care) for issues that could be treated in a primary care setting and hospitalization of ambulatory sensitive conditions; and (4) bring all providers up to attainable benchmarks of quality and value by narrowing the variation in practice and adoption of best practices. The pilot programs outlined above demonstrate that the medical home model offers considerable promise in helping to achieve these goals.

Commonwealth Fund-supported evaluations show that advancing the spread of PCMHs will require:

1. certification of primary care practices as PCMHs;

2. incentives for enrollee designation of medical homes

3. new payment methods for PCMHs

4. support PCMHs within actual or virtual organized care system; and

5. support for adoption and implementation of information systems.

Fortunately, a number of the items listed above are becoming available for primary care physicians and groups. The National Committee for Quality Assurance has adopted a certification program for patient-centered practices. The Bridges to Excellence program offers financial rewards for meeting the National Committee for Quality Assurance standards. The link between payment reform and delivery system reform is now well-established. ${ }^{17}$ Similarly, the need to narrow compensation levels between primary care and specialty care is reflected in health reform provisions in both the House of Representatives and the Senate. ${ }^{1}$ Health reform represents a historic opportunity not only to close the gaps in health insurance coverage, but to align financial incentives and transform care delivery in ways that enhance clinical quality, patient experiences, and value.

Policy leaders agree that a robust and organized system of primary care is at the center of a highperformance health system. As reform advocates seek to lower costs, increase access, and improve quality in the American system, family physicians will continue to be called on to lead change and advance patient-centered care models. Although the United States as a whole has not performed well on key metrics of patient-centered care, numerous demonstration projects and areas of excellence provide important lessons for the health professional community going forward. The PCMH model is a promising avenue for reform that improves patient experiences of care, clinical outcomes, and physician satisfaction with medical practice. National leaders must continue to seek out and provide the financial and technical assistance necessary to spread its adoption.

\section{References}

1. Davis K, Guterman S, Collins SR, Stremikis K, Rustgi S, Nuzum R. Starting on the path to a high performance health system: analysis of health system reform provisions of reform bills in the House of Representatives and Senate. New York: The Commonwealth Fund; 2009.

2. Green LA, Graham R, Bagley B, et al. Report of the Task Force on Patient Expectations. Core values, reintegration, and the new model of family medicine. Ann Fam Med 2004;2(Suppl 1):533-50.

3. American Academy of Family Physicians. Joint principles for the patient-centered medical home released by organizations representing more than 300,000 physicians. Available at http://www.aafp. org/online/en/home/media/releases/2007/20070 305 pressrelease $0 . h t m l$. Accessed 21 January 2010.

4. Nutting PA, Miller WL, Crabtree BF, et al. Initial lessons from the First National Demonstration Project on practice transformation to a patient-centered medical home. Ann Fam Med 2009;7:3:25460.

5. Davis K, Schoenbaum SC, Audet AM. A 2020 vision of patient-centered primary care. J Gen Intern Med 2005;20:953-7.

6. Peterson M. A manpower policy for primary health care: a commentary from the American College of Physicians. Ann Intern Med 1980;84:843-51. 
7. Institute of Medicine. Primary care: America's health in a new era. Washington: National Academy Press; 1996.

8. Starfield B. Primary care: balancing health needs, services, and technology. New York: Oxford University Press; 1999.

9. Showstack J, Rothman AA, Hassmiller SB. The future of primary care. San Francisco: Jossey-Bass; 2004.

10. Davis K, Schoen C, Schoenbaum SC, et al. Mirror, mirror on the wall: an international update on the comparative performance of American health care. New York: The Commonwealth Fund; 2007.

11. The Commonwealth Fund Commission on a High Performance Health System. Why not the best? Results from the National Scorecard on US health system performance, 2008. New York: The Commonwealth Fund; 2008.

12. Schoen C, Osborn R, Doty MM, Bishop M, Peugh J, Murukutla N. Toward higher-performance health systems: adults' health care experiences in seven countries, 2007. Health Aff (Millwood) 2007;26: w717-34.

13. Schoen C, Osborn R, How SKH, Doty MM, Peugh J. In chronic condition: experiences of patients with complex health care needs in eight countries, 2008. Health Aff (Millwood) 2009;28:w1-16.

14. Schoen C, Osborn R, Trang Huynh P, Doty M, Peugh J, Zapert K. On the front lines of care: primary care doctors' office systems, experiences, and views in seven countries. Health Affairs (Millwood) 2006;25:w555-71.

15. Davis K, Stremikis K. Health information technology: key lever in health system transformation. New York: The Commonwealth Fund; 2009.

16. Davis K, Doty MM, Shea K, Stremikis K. Health information technology and physician perceptions of quality of care and satisfaction. Health Policy 2009; 90:239-46.

17. Shih A, Davis K, Schoenbaum S, Gauthier A, Nuzum R, McCarthy D. Organizing the U.S. health care delivery system for high performance. New York: The Commonwealth Fund; 2008.

18. How SKH, Shih A, Lau J, Schoen C. Public views on U.S. health system organization: a call for new directions. New York: The Commonwealth Fund; 2008.
19. McCarthy D, Mueller K. Organizing for higher performance: case studies of organized delivery systems. New York: The Commonwealth Fund; 2009.

20. Davis K. Closing the quality chasm: opportunities and strategies for moving toward a high performance health system. Invited testimony to Senate Committee on Health, Education, Labor, and Pensions Hearing on "Crossing the Quality Chasm in Health Care Reform." 29 January 2009.

21. Davis K. Learning from high-performance health systems around the globe. Invited Testimony to Senate Committee on Health, Education, Labor, and Pensions; 2007.

22. TransforMED [Homepage.] Available at http:// www.transformed.com. Accessed 21 January 2010.

23. Reid RJ, Fishman PA, Yu O, et al. Patient-centered medical home demonstration: a prospective, quasiexperimental, before and after evaluation. Am J Manag Care 2009;15:e71-e87.

24. Paulus RA, Davis K, Steele GD. Continuous innovation in health care: implications of the Geisinger experience. Health Aff 2008;27:1235-45.

25. Moody G, Silow-Carroll S. Aiming higher for health system performance: a profile of seven states that perform well on the Commonwealth Fund's State Scorecard. New York: The Commonwealth Fund; 2009.

26. McCarthy D, Nuzum R, Mika S, Wrenn J, Wakefield $M$. The North Dakota experience: achieving high-performance health care through rural innovation and cooperation. New York: The Commonwealth Fund; 2008.

27. Share D. A Blue Cross Blue Shield of Michigan model for physician payment and health care delivery system reform. Southfield, MI: Blue Cross Blue Shield of Michigan; 2009.

28. Kaye N, Takach M. Building medical homes in state Medicaid and CHIP programs. Washington, D.C.: National Academy for State Health Policy; 2009.

29. Kaiser Commission on Medicaid and the Uninsured. Community Care of North Carolina: putting health reform ideas into practice in Medicaid. Washington: Kaiser Family Foundation; 2009.

30. Hallek M. Typical problems and recent reform strategies in German health care - with emphasis on the treatment of cancer. Presentation to the Commonwealth Fund International Symposium, Washington, DC, November 2, 2006. 